\title{
Debate sobre a teoria da renda da terra no contexto agrícola, urbano e atual no Brasil
}

\author{
Debate on the theory of land rent in the agricultural, \\ urban and current context in Brazil
}

Edmar Augusto Santos de Araujo Júnior [l]

\begin{abstract}
Resumo
Este artigo apresenta o debate sobre a teoria da renda da terra, partindo do caso agrícola, passando pela teoria da renda do solo urbano, abordando suas modalidades e magnitudes à luz da teoria do valor. A renda capitalizada no preço do solo condensa um fundo de valor social cuja magnitude se expressa em função de variáveis macroeconômicas pela sua capacidade de interferir direta ou indiretamente nos salários e lucros. Essa abordagem teórica permite concluir sobre os efeitos econômicos do projeto de lei, em tramitação, que permite a aquisição das terras municipais pelo capital estrangeiro no Brasil.
\end{abstract}

Palavras-chave: teoria do valor; propriedade privada da terra; renda da terra agrícola; renda do solo urbano; capital estrangeiro.

\begin{abstract}
This article presents the debate on the theory of land rent. It starts from the agricultural case and addresses the theory of urban land rent, approaching its modalities and magnitudes in light of value theory. The capitalized income in the price of land condenses a social value fund whose magnitude is expressed according to macroeconomic variables due to its capacity for interfering directly or indirectly in wages and profits. This theoretical approach allows us to analyze the economic effects of a bill pending in the Senate that allows the acquisition of municipal lands by foreign capital in Brazil.
\end{abstract}

Keywords: value theory; private land ownership; agricultural land rent; urban land rent; foreign capital. 


\section{Introdução}

A dimensão econômica explica dois aspectos-chave dos usos do solo: o papel da propriedade privada e a apropriação de valor excedente na produção capitalista do espaço urbano. A teoria do valor introduz a teoria da renda da terra, ao revelar como o lucro, o elemento base da distribuição do valor, torna-se renda da terra, através do estatuto da propriedade privada, que transcende a renda da terra agrícola, manifestando-se também na produção do espaço urbano.

A dupla mercadoria moderna, a terra urbana e o espaço construído, torna o solo em um ativo potente para instrumentalizar a participação no valor excedente. A renda da terra, embora pouco sistematizada e relacionada pela literatura contemporânea com as variáveis macroeconômicas, é capaz de influenciar a taxa de lucro média e interferir nos salários reais dos municípios e metrópoles brasileiras. Os recursos da renda da terra podem ser investidos em capital fixo (urbano e rural), incentivando investimentos produtivos, barateando o preço da terra infraestruturalizada para a classe trabalhadora, tornando o salário real mais valorizado.

Os imbricamentos macroeconômicos causados pela renda da terra sobre o processo de acumulação de capital e divisão do valor entre salários e lucros foram primeiramente constatados por David Ricardo, em 1817, que avançou sobre o conceito de renda diferencial. Ricardo explicou como a renda se constituía como uma função da taxa de juros, sobre o retorno do capital, que acabava diminuindo as bases da acumulação capitalista, ao direcionar uma parte dos lucros dos capitalistas agrícolas aos proprietários de terras.
Karl Marx, em 1867, constatou que a renda da terra não decorria da remuneração de um fator de produção, mas sim do pagamento pela permissão de uso, aprofundando a teoria da renda diferencial inaugurada por Ricardo. O seu conceito de renda absoluta foi capaz de explicar o paradoxo aparente de a terra se tornar uma mercadoria que tem preço, mesmo sem ter valor, por ser irreprodutível e não ser expressão direta da ação do trabalho humano.

Os adeptos de posições ricardianas e marxistas tendem a convergir a favor $d a$ recuperação da renda da terra, por configurar um enriquecimento sem causa, que se torna possível graças aos institutos jurídicos da propriedade privada e da herança da terra, consistindo em obstáculos tanto para o capital, quanto para os trabalhadores.

O aporte teórico oferecido por Jaramillo (2009) concilia alguns pressupostos (neo)clássicos e (neo)marxistas, reformulando a Teoria Geral da Renda da Terra (TGRT) para explicar a origem e as modalidades de renda posteriormente associadas à terra urbana. A existência social da propriedade territorial no capitalismo, como uma representação não espontânea desse fenômeno, manifestando-se primeiramente no caso da terra agrícola, é o ponto de partida para a formulação de uma Teoria da Renda do Solo Urbano (TRSU), que dialoga com Singer (1982), Topalov (1981), Almeida e Monte-Mór (2017), dentre outros.

A renda recebida pelos proprietários de terra é uma manifestação da natureza da propriedade privada do solo, ancorada sob o marco da produção na moderna agricultura capitalista e de sua complementaridade à produção industrial. A consolidação de uma classe social compreendida por proprietários de terras, que 
recebe uma renda periódica, como porção do trabalho social, somente pelo domínio jurídico sobre a posse dos terrenos, cujos atributos diferenciais permitem a cobrança de rendas extraordinárias, originou um fenômeno social moderno: uma renda capitalista em que a posse da terra é associada à posse de capital e, por isso, deve ser remunerada, tal como uma proporção dos demais componentes do valor: salários e lucros.

A renda da terra é entendida, então, como uma parte do excedente social, da mais-valia extraída pelos capitalistas, que, ao invés de se tornar lucro, vai parar nas mãos dos proprietários, como condição da autorização do acesso à terra para a produção. A terra é irreprodutível, ela é objeto e meio de produção ao mesmo tempo e está fora do controle dos capitalistas. Mesmo não podendo ser reproduzida, ela é passível de ser monopolizada e apropriada individualmente, exercendo uma condição de acumulação externa ao capital.

A terra torna-se uma mercadoria que tem um preço comercializável no mercado, mas sem representar, em seu valor, uma porção direta do trabalho social. Esse é o paradoxo da mercantilização da terra apontado pela tradição marxista, na medida em que ela adquire um preço no mercado, em função da existência da renda da terra. Isto é, o preço do solo torna-se um mecanismo de capitalização da renda, sendo possível investigar sua natureza e suas causas.

A formação da renda da terra na agricultura e a sua manifestação no contexto urbano revelam como pode adquirir uma apropriação de valor por aqueles que detêm ou monopolizam a sua propriedade da terra. Esse processo de apropriação indevida da renda da terra pode ser ainda mais dramático se ela for monopolizada pelo capital estrangeiro, como prevê o Projeto de Lei em marcha no Senado Federal brasileiro.

\section{A origem da renda da terra}

A existência da renda do solo urbano deve ser contextualizada pelo advento das relações de produção capitalista na agricultura, de modo a especificar, brevemente, em que circunstâncias, sob que modalidades, em que magnitude e com relação a quais processos, o proprietário de terra exige uma renda do capitalista.

0 preço do solo é fixado pela capacidade que tem o proprietário de receber uma quantidade de valor periodicamente, através de uma quantia de dinheiro, que não se diferencia daquela auferida pelos juros recebidos pelo proprietário de um capital real. Ante a existência de uma taxa de juros, o proprietário associa sua posse de terra à posse de capital, que lhe daria a soma em juros o que ele recebe em renda.

A propriedade privada da terra funciona tal como um título de crédito no mercado financeiro, que permite, ao seu proprietário, auferir renda periódica, podendo o bem ser transacionado por um preço proporcional àquela renda, através de um fator de proporcionalidade dado pelas taxas de juros vigentes no mercado de crédito. 0 preço do solo configura uma renda, que a propriedade proporciona, capitalizada por determinada taxa de juros para a remuneração de um determinado capital. $\mathrm{O}$ uso do solo é regulado pelo mercado imobiliário, e a formação do preço corresponde ao acesso, mediante compra do título ou pagamento periódico de aluguel, para a utilização do espaço (Singer, 1982). 
No modelo simplificado e abstrato de determinação da renda da terra compatibilizado por Jaramillo (2009), o preço do solo emerge no mercado, mas o que se transaciona, mais do que a terra, é o direito de receber uma renda. 0 preço do solo (PS) expressa-se no mercado como a renda ( $r$ ) dividida pela taxa de juros (i): PS= r/i. Na análise sobre a propriedade territorial, o mais importante não é o preço do solo e, sim, a renda, uma vez que é a magnitude da renda que determina a magnitude do preço. Por isso é importante este debate para refletirmos sobre as políticas de estímulo à aquisição estrangeira de propriedade fundiária.

Supõe-se um aporte de capital para a produção agrícola, em um determinado lote de terreno. Do Capital Total, um montante é utilizado para comprar Capital Constante (insumos, máquinas, combustível), e o outro para comprar Capital Variável (salário da força de trabalho). A taxa de lucro (g) é um componente do valor e expressa a relação entre a mais-valia e o Capital Total. A apropriação desse lucro, que é parte da mais-valia total gerada na economia, é proporcional ao capital investido, sendo a taxa de lucro precisamente uma medida dessa proporção.

O valor da produção consiste no montante obtido com a remuneração da soma dos três componentes do valor: capital variável (salário), capital constante (juros) e mais-valia (lucro). O Preço de Produção (PP) forma-se através de um procedimento técnico e é o mais eficiente disponível entre os competidores, mas é menor do que o Preço de Mercado (PM), que é determinado pelas terras mais rentáveis. 0 preço de produção (PP) consiste no preço pelo qual os capitalistas vendem o volume da produção, considerando o capital investido ( $k$ ) mais a taxa de lucro: $P P=k(1+g)$.

A hipótese de competição capitalista é importante, pois há uma diferença técnica da composição orgânica de capital ${ }^{1}$ entre os setores e ramos da economia, garantindo no médio prazo que o capital migre de um setor em busca de maior rentabilidade. Esse equilíbrio, via taxa de lucro, altera os níveis de produção, permitindo que o preço de produção se iguale ao preço de mercado. Qualquer desajuste nessa equação leva os capitalistas a abandonarem seus setores para outros que apresentem taxas de lucro mais elevadas, aumentando a produção, até que seu preço caia e haja ajuste novamente entre os setores.

Considera-se, inicialmente, que os lotes de terra, em que cada capitalista opera, não tenham nenhum preço. Parte do capital constante é utilizado para alugar uma máquina de geração de energia necessária para a produção. Alguns terrenos, entretanto, possuem queda de água, que pode ser utilizada para a geração dessa energia, permitindo ao capitalista economizar esse montante para pagar a máquina, gerando um lucro extraordinário.

O capitalista instalado nessa terra, com queda d'água e geração autônoma de energia, opera com menores custos e com um lucro excepcional, que é possível apenas pelas características físicas do terreno. 0 proprietário desse terreno, ciente disso, e num cenário de concorrência, cobrará uma parte desse sobrelucro como condição de acesso à terra. No limite, algum capitalista estará disposto a ceder todo o sobrelucro ao proprietário, sendo indiferente produzir em um lote normal ou nesse com queda d'água. 
Pela característica paradoxal da terra, de ser uma mercadoria que possui preço, mesmo sem ser produto do trabalho, a renda do solo surge em terrenos privilegiados. 0 fenômeno jurídico da propriedade permite, aos proprietários, controlar as circunstâncias que geram lucro excepcional, viabilizando uma transferência de valor que seria apropriado pelos capitalistas. A propriedade privada permite transformar lucro extraordinário em renda da terra.

A terra com características produtivas excepcionais, que produz com menores custos em condições relativas, quando comparada aos demais terrenos, é limitada e, por isso, surge a renda, representada por uma porção da mais-valia total que os proprietários conseguem fazer escapar dos capitalistas. A renda é estabelecida sobre o lucro médio e uniforme e, por isso, está associada ao lucro total dos capitalistas na economia. Até os setores capitalistas que não utilizam terra para operar sua produção se apropriam de uma mais-valia que poderia ser maior não fosse a renda da terra, devido aos efeitos em cascata que a competição gera entre os setores, através dos ajustes nos preços e lucros.

\section{As modalidades da renda da terra agrícola}

A primeira modalidade, prevista desde Ricardo, ao abordar a incorporação produtiva de terrenos marginais, é a Renda Diferencial (RD) tipo 1, que se refere ao papel desempenhado pela fertilidade diferenciada entre os lotes de terras. Essa diferenciação é capaz de gerar um efeito semelhante ao das terras com queda d'água e geração autônoma de energia.
A diferença de fertilidade entre os lotes permite maiores lucros, assim como aqueles que produzem em terrenos com melhores localizações também podem diminuir seus custos com transporte, aumentando consequentemente seus lucros.

Essas circunstâncias, que são alheias ao controle do capital, pois estão subordinadas à propriedade privada da terra, geram, no curto prazo, lucros extraordinários associados às condições diferenciais de produção dos terrenos. A categorização tipo 1 refere-se à aplicação de montantes de capital similares, que se denomina uma cota normal de capital sobre a terra.

O critério da fertilidade faz com que haja um mercado de terras marginais que opera a uma produtividade limite em relação às terras mais produtivas, mas que ainda geram lucros, justificando os investimentos de capital. Diante da renda diferencial, são as condições de produção aplicadas aos terrenos marginais, cuja renda diferencial é nula, que regulam o preço do mercado. Isto porque a renda implica um sobrepreço, que o consumidor paga como se todos os bens tivessem sido produzidos nas piores terras. Como o preço de mercado é uniforme, ele acaba sendo aplicado aos bens produzidos nas melhores terras, nas quais o preço de produção é inferior.

A Renda Diferencial (RD) tipo 2 refere-se à magnitude da renda, em virtude de um aumento na quantidade de capital aplicado à terra. A intensidade diversa de capital total sobre a terra estaria associada a uma distribuição desigual de capital entre os capitalistas agrícolas. 0 aumento da intensidade de capital total, constante e variável, investido sobre o mesmo lote de terra, consiste, então, em uma razão entre o capital total e a quantidade de terra. 
Em relação àquele que opera sob uma cota normal, o capitalista intensivo em capital gera o dobro da produção física e de lucro médio, que se convertem em renda ao proprietário desse terreno. Esse capitalista, em condição de acumulação superior, obtém um lucro extraordinário, mas a competição, no médio prazo, com a entrada de outros capitalistas, em grau de acumulação similar, faz com que o mercado se reequilibre, através dos reajustes de preço e lucro, pela migração de capitais entre os setores em busca de maiores retornos.

Essa intensidade de capital superior seria análoga ao que ocorre com as inovações tecnológicas: os capitalistas que operam com melhores técnicas se apropriam de lucros extraordinários, durante um tempo, até que os concorrentes consigam igualar o padrão tecnológico, fazendo com que o lucro se converta em renda diferencial do tipo 2 . Os proprietários de terra seriam capazes também de se apropriar desse lucro.

Essa modalidade articulada de renda diferencial só ocorreria porque existe o tipo 1 . É preciso haver, de antemão, uma heterogeneidade de terras para haver um lucro extraordinário que se converta, posteriormente, em renda diferencial do tipo 2 , em terrenos mais férteis onde se pretende intensificar a produção com acréscimos de capitais.

A Renda Absoluta (RA) da terra é considerada uma das grandes contribuições do pensamento de Marx às análises econômicas sobre o mercado de solo, de um modo geral. A constatação de que mesmo as terras mais estéreis e longínquas apresentavam um preço e que, para sua utilização, tinham de ser pagas rendas positivas, na moderna agricultura capitalista britânica ${ }^{2}$ do século
XIX, fazia com que a conclusão ricardiana de renda nula na terra marginal fosse pouco intuitiva praticamente.

Uma fonte adicional de rendas, que está presente mesmo nas terras que não oferecem vantagens produtivas relativas, está associada ao fenômeno social da instituição da propriedade privada da terra. Não se trata de um fenômeno técnico, como no caso da renda diferencial, que está sustentada pela diferença de vantagens produtivas que os lotes apresentam, fazendo com que seja possível, no final do processo, vender acima do preço de produção.

No caso da renda absoluta, o poder de retenção que outorga, aos proprietários, o domínio jurídico sobre a terra permite que eles exijam uma renda como condição para fornecerem seus terrenos à produção, e tem como sustento a escassez (finitude) de terras. Essa retenção, que independe da heterogeneidade produtiva da terra, leva a um sobrepreço que se repercute em renda. A renda absoluta tende a uma magnitude uniforme entre os terrenos e, apesar da natureza e de determinantes distintos, interatua de maneira simultânea com a renda diferencial (I+II) no mercado de terras.

Os terrenos tenderiam a uma Renda Total (RT), em que as rendas (absoluta e diferenciais I e II) se agregariam, sendo que nos terrenos marginais, cuja renda diferencial é nula, só se manifesta a renda absoluta. Sem a renda absoluta, os proprietários subtrairiam seus terrenos das estruturas produtivas, gerando um desequilíbrio entre oferta e demanda, levando a um aumento brusco nos preços dos produtos agrícolas. A magnitude da renda absoluta depende do quanto os consumidores estarão dispostos a pagar pelos bens agrícolas nesse ajuste entre o preço ofertado e a quantidade demandada. 
A renda absoluta é estrutural no capitalismo e o preço de mercado supera o de produção, inclusive nas terras marginais, fazendo com que o seu resultado seja em função da confrontação entre oferta e demanda. 0 preço de mercado difere de maneira estável, convergindo ao preço de produção, para haver a renda absoluta, mas sem superar, todavia, o valor (salários, juros e lucros). As transferências de mais-valia entre os setores, de acordo com a composição orgânica do capital e das distintas taxas de lucros, mostram que o valor e o preço de produção, em cada setor, estão relacionados.

Estruturalmente, a existência de rendas positivas é que justifica a propriedade privada da terra, que não é outra coisa, senão o poder de receber a renda. A apropriação e transação da terra, enquanto mercadoria, refere-se à prerrogativa de capturar a renda gerada pelas relações capitalistas.

A renda absoluta e a renda diferencial não são sobrepostas, como acreditava Marx, pois ambas as formas de rendas são manifestações quantitativas de um mesmo mecanismo econômico. A escassez e a irreprodutibilidade de terras são características que a competição capitalista não controla e consistem em fatores de produção que entrelaçam os direitos jurídicos aos efeitos econômicos sobre a terra. Pode haver uma escassez relativa (a expansão da produção encontra terras em condições piores) ou absoluta (a irreprodutibilidade impede a expansão), que explicariam cada tipo de renda (Jaramillo, 2009).

0 regime jurídico da propriedade privada da terra, concentrada em torno de uma classe de proprietários, em que está prevista uma série de direitos, como de transmissibilidade, alienabilidade, edificabilidade, etc., foi sendo construído socialmente e de forma coerente ao sistema do capital. A propriedade privada permite controlar os aspectos irreprodutíveis da terra. A razão para a formação da renda absoluta sustenta-se na capacidade que têm os proprietários de fazer valer o domínio exclusivo da terra, exigindo uma parte do lucro dos capitalistas e cobrando um preço, superior ao de produção, dos consumidores para produzirem nas terras menos favorecidas.

A Renda de Monopólio (RM) reside na escassez de terras. Ela pode ser focalizada (quando restrita a uma região específica) ou generalizada (quando aplicada à escassez absoluta de terras disponíveis para a produção). Essa escassez representa uma barreira à ampliação produtiva, gerando sobrepreço nos bens agrícolas, que se converte em renda ao proprietário. 0 exemplo clássico desse tipo de renda consiste na produção de vinhos da região de Champagne, na França.

São produtos reconhecidos mundialmente pelos consumidores, devido às características agroecológicas e climáticas das terras limitadas da região, que garantem um vinho de altíssima qualidade. Para não haver desabastecimento, os consumidores estão dispostos a pagar um preço de mercado muito superior ao preço de produção, devido à quantidade produzida limitada e ao fetiche criado em torno do status ou do sentimento que o consumo desse produto proporciona.

0 preço de mercado, nesse caso, não é regulado por nenhum setor produtivo e não está relacionado estritamente ao funcionamento estrutural da lei do valor, e sim por um desajuste eventual expresso pelas forças excepcionais da oferta sobre a demanda. Como esse sobrelucro é justificado pelas características escassas da terra, os proprietários 
estarão em condições excepcionais, através da competição entre capitalistas, de se apropriarem do sobrelucro sob a forma de renda da terra. Uma parte da mais-valia é apropriada do fundo geral de acumulação de capital, em seu conjunto.

O Gráfico 1 ilustra o comportamento das modalidades das rendas da terra agrícola (diferenciais I e II, absoluta e de monopólio) em relação ao preço do mercado, ao preço de produção e ao valor. Na escala vertical, o ponto mais alto corresponde ao preço de mercado (PM) e o preço mais baixo, ao de produção (PP); e a linha intermediária corresponde aos elementos responsáveis pela realização do valor. O lucro convertido em renda, diante da fertilidade, que aumenta conforme se distancia do intercepto horizontal, agrega as modalidades na seguinte equação: $R T=R D(I+I I)+R A+R M$.

Como a competição capitalista não absorve parte do sobrelucro gerado nas melhores terras, a propriedade econômica da terra emerge como fenômeno social capaz de capturar o sobrelucro transvestido de renda. Os proprietários são capazes, inclusive, de incidir na magnitude dessa renda, com medidas articuladas de retenção do solo, gerando escassez artificial de terras.

Gráfico 1 - Relação entre preços agrícolas e lucros transformados em rendas da terra

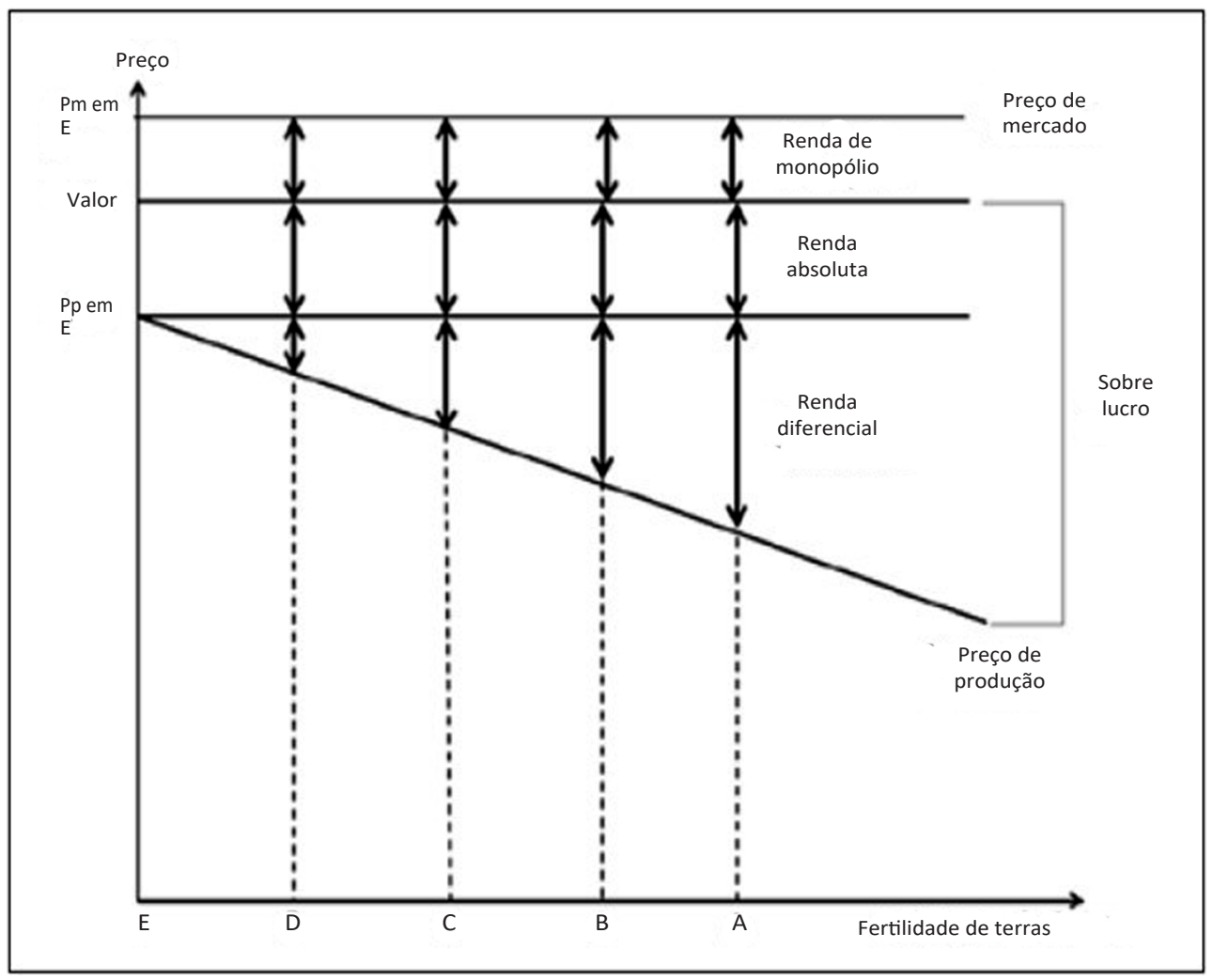

Fonte: Guigou (1982 apud Almeida e Monte-Mór, 2007). 
O foco na propriedade privada, em um contexto de produção capitalista generalizado, sobretudo do espaço urbano construído, permite compreender como a renda da terra desempenha um papel regulador da competição capitalista e dos fluxos de capitais em setores em que aspectos irreprodutíveis não controlados pelo capital geram sobrelucro. Mas isso não esconde o seu caráter parasitário, dado o conflito aparente entre proprietários e capitalistas e sua intervenção no processo de acumulação de capital.

Compreender a renda da terra no contexto de suas categorias gerais permite analisar como as rendas tomam corpo no contexto do solo urbano. Com o fenômeno social da propriedade privada da terra, as rendas absoluta, diferencial e de monopólio devem ser consideradas na construção de instrumentos de políticas do solo. A renda absoluta aparece uniforme, já a diferencial depende de localização, usos e aproveitamentos, etc.

\section{A renda da terra na produção do espaço urbano}

Nas cidades, a existência social da terra consiste em sua capacidade de gerar espaço, servindo como lugar físico e suporte à produção de espaço construído para o desenvolvimento de atividades urbanas. A cidade não é o espaço em si mesmo e nem pode ser reduzida ao lugar do mercado. Os homens preparam a terra urbana, através do trabalho social, do dispêndio de energia e de insumos produtivos e constroem o espaço, edificando-o.

A cidade constrói-se, então, sob a forma de um "ente social", subordinada ao processo de acumulação de capital, impondo a cada um de seus componentes a assumir uma expressão da acumulação privada. A monopolização jurídica e a apropriação privada do solo urbano constituem-se como condicionantes iniciais à existência da renda do solo urbano.

A manifestação da renda da terra nas cidades torna-se um ponto de inflexão importante para a acumulação de capital, na medida em que determinadas estruturas fundiárias urbanas podem facilitar o sobrelucro ou simplesmente repelir o processo de acumulação, sobretudo em locais em que a renda é alta o suficiente para interferir nas taxas de lucro e nos salários reais, com custos de aluguéis e transportes.

A terra no contexto urbano está conectada ao produto "espaço construído", devido a sua longa vida útil e a sua imobilidade, e ambos são transformados em uma mercadoria única, no momento do consumo. 0 setor de acumulação de capital, no qual se conecta a terra urbana, revela o processo de geração da renda do solo urbano em que o seu uso está associado. ${ }^{3}$ Há uma relação entre os preços do solo com o nível de capital (fixo e móvel) aplicado à terra, à remuneração dos fatores de produção e às atividades desempenhadas nos espaços construídos. Essas atividades são determinadas por variantes estruturais, práticas coletivas, convenções sociais e funcionalidades técnicas.

O capital, em seus diversos ramos, buscou se apropriar da renda da terra, que era captada pelos proprietários originais, financeirizando o setor imobiliário, criando agentes da especulação e subordinando o Estado a corroborar seus interesses de acumulação. A propriedade privada da terra adquire um papel adicional na consolidação das relações 
capitalistas, na construção do espaço urbano. O capital tende a destruir as formas não mercantis, sobretudo, por privilegiar uma convergência entre o consumo do espaço construído com a propriedade privada do solo. Os proprietários urbanos não são caracterizados como uma classe social homogênea, como no caso agrícola. A fragmentação dos títulos de propriedade os deixa com interesses não convergentes.

Ao colocar o terreno à disposição do capitalista construtor, o proprietário urbano pode barganhar uma parte do produto social, capturando uma parte da mais-valia envolvida no processo de produção do espaço construído, sob a forma de renda, capitalizada através do preço do solo. 0 capital pressiona para que a propriedade urbana tenha um caráter privado, de modo a permitir a mercantilização dupla: do solo e do espaço construído.

Essa pressão de subordinar o valor de uso ao valor de troca, no entanto, tal como já apontara Lefebvre (2000), esbarra na característica transcendental e na dimensão histórica da cidade, de possuir um valor de uso de caráter coletivo, por ser o local de interação e projeção espacial das relações sociais. Essa característica da cidade não pode ser rompida pelo capital, pois contrariaria seus interesses de acumulação.

As práticas espaciais requerem uma referência coletiva que escapa ao controle do capital, no processo de produção do espaço construído. Ao mesmo tempo, as diferentes potencialidades de cada terreno não dependem dos agentes envolvidos nesse processo. 0 consumo do espaço construído, mediado pela propriedade privada, é afetado pela inserção de cada lote, em uma determinada estrutura de alocação de usos do solo com preços diferenciados, que se transformam em rendas para o proprietário.

A Figura 1 revela o processo de formação da renda do solo urbano e a financeirização dessa renda através de dois eixos: a repartição da renda desde a negociação com o proprietário original do terreno com os demais agentes (incorporador, capital bancário, seguradora e construtor) e a relação de produção do espaço entre o construtor e os trabalhadores assalariados da construção civil, onde o valor é gerado.

Impulsionada pela acumulação de capital e estruturada pela contraposição capital-trabalho assalariado, o setor da construção urbana defronta-se com algumas barreiras e limitações à produção. A principal delas consiste no período prolongado de rotação de capital, sobretudo, com relação ao processo de adequação e equipamento do terreno, afetando a magnitude das taxas de lucro e a produção em escala.

O preço do produto "espaço construído" aumenta por essas questões e, também, para garantir o recebimento de renda pelo proprietário. Como o mercado espontâneo é estreito e o preço elevado, um impacto sobre as condições de acumulação e um atraso técnico relativo do setor da construção são gerados, em comparação a outros setores intensivos em capital. As condições que limitam a demanda requerem um capital de circulação para financiar o consumo de habitação e de dispositivos políticos e jurídicos que garantam um fluxo de terras.

Os capitalistas tendem a contingenciar os processos de incrementos de capital constante, de inovação tecnológica e de maquinação, 
Figura 1 - Relações de produção e repartição da renda do solo urbano

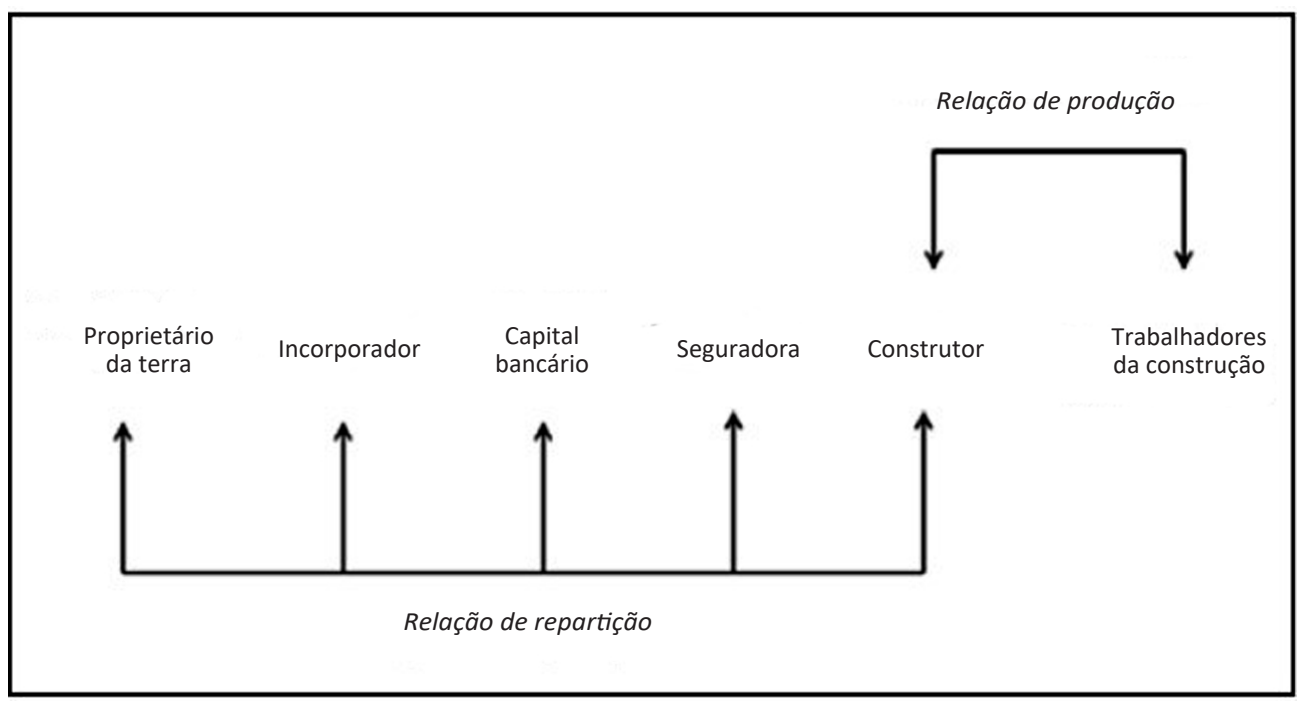

Fonte: Guigou (1982 apud Almeida e Monte-Mór 2017).

preferindo apostar em várias ações pequenas e pulverizadas, nas quais o trabalho manual e intensivo prevalece. 0 processo de acumulação de capital requer agentes que são envolvidos para superar as barreiras e os limites à demanda, que tendem a deslocar o capital produtivo do controle da produção.

O Estado é induzido a ser o produtor dos espaços construídos necessários para a reprodução geral do capital, sendo acionado para facilitar a acumulação, resolver os limites da demanda e promover os ajustes urbanos necessários para a oferta de terras. Quando o capital não encontra demanda solvável, que garanta taxas de lucro suficiente para viabilizar a produção, a mercantilização do espaço construído é relegada ao Estado. As políticas públicas da produção do espaço urbano, através de obras de urbanização, dos programas de habitação popular, além das práticas de mutirão, da autoconstrução, etc. são alternativas à falta de interesse do capital.

Apresentamos as articulações e as modalidades de renda do solo urbano consolidadas por Jaramillo (2009) em que a terra urbana é estruturada por articulações primária e secundária que movimentam magnitudes de rendas específicas. A articulação secundária sobrepõe-se à primária para formar o que seria uma "articulação complexa do solo urbano". 


\section{As modalidades de renda \\ na articulação primária do solo urbano}

A articulação primária está ligada ao processo produtivo da edificação pela indústria da construção e permite o surgimento de três tipos de rendas primárias do solo urbano. A Renda Primária Diferencial tipo 1 está associada às características individuais dos terrenos. É semeIhante ao caso da fertilidade dos terrenos agrícolas, referindo-se às condições diferenciais de "localização" e "construtibilidade", que cada terreno apresenta, que podem ser favoráveis à edificação e ao consumo do espaço.

A construtibilidade diferenciada ocorre pelas características geomorfológicas, traduzindo-se em taxas de lucro mais vantajosas ao capitalista, comparadas aos custos maiores relativos à construção em outros terrenos desfavoráveis. As vantagens de localização, que permitem uma renda diferencial para os proprietários dos terrenos, referem-se aos valores de usos das infraestruturas e dos serviços urbanos.

Nessa busca pelos melhores terrenos, o preço passa a ser regulado pelas condições de produção nos piores terrenos, aqueles menos construíveis e os mais longínquos das redes de abastecimento e serviços infraestruturalizados. A "escala de preços" tende a reagir menos a essa modalidade de renda. 0 fator da localização pode ser recuperado por instrumento estatal, já que essa renda consiste exatamente no que o proprietário tem que pagar pelos custos de infraestrutura.

A Renda Primária Diferencial tipo 2, tal como no caso agrícola, refere-se à intensidade diferenciada de capital aplicado à terra, relacionando-se à construção em altura. 0 fenômeno da verticalização, que multiplica espaços construídos em um mesmo lote, revela uma associação entre a densidade construtiva e a magnitude dos preços do solo. A decisão técnica entre a opção de construir em baixa densidade ou em altura, ainda que sofra os efeitos da regulação urbanística, é definida pelo custo de produção das técnicas de construção em altura diversa e pelos preços heterogêneos do espaço construído, nas diferentes localidades.

Essa diferença de preço em cada localização por espaços construídos muito similares gera um lucro ao capitalista que pode se converter em renda ao proprietário. Caso o preço do espaço não seja alto o suficiente para compensar os maiores custos de se produzir em altura, a opção será construir em baixa densidade, pois é a relação entre custos de produção e preços de venda do espaço construído que determina a densidade e o preço do solo (Jaramillo, 2009).

A cota adicional de capital sobre a terra para construir em determinados níveis de altura (baixo, alto, altíssimo) e o lucro potencial da construção dependem da disposição dos consumidores a pagar pela localização específica do terreno. Dado o preço do espaço construído, o mercado determina o mínimo e o máximo da edificabilidade, de acordo com a possibilidade de gerar uma renda máxima. A "edificabilidade econômica" consiste no nível que maximiza essa renda. Os agentes mercantis tendem a adotá-la, mas isso não se traduz necessariamente em um ponto máximo em altura da edificação, pois, a partir de um ponto, a renda diminui com o aumento da edificação. 
Conforme se aumenta o preço unitário do espaço construído, cresce o nível de edificabilidade em que a renda é máxima. Há, então, uma regulação simultânea entre os níveis de edificabilidade e renda para cada preço do espaço construído. Os níveis de densidade representam as cotas de capital aplicadas à terra, sendo a técnica de baixa densidade a que corresponde à cota normal de capital.

A Renda Absoluta Urbana (RAU) é capaz de explicar a existência do nível de renda mínima dos terrenos urbanos, uma vez que, mesmo as terras que não possuem nenhuma vantagem relativa para a construção, apresentam rendas positivas. A terra destinada ao uso urbano, em contraposição ao uso rural, já proporciona uma renda superior ao que seria destinado para uma finalidade agrícola. Imaginando que esses terrenos estejam situados nos limites da cidade com o campo, o limite mínimo da renda absoluta urbana será a magnitude da renda rural das terras cercando a cidade (ibid.).

A oferta de terrenos escapa ao controle do capital promotor e, mesmo que haja terras disponíveis para expansão da cidade, são necessários equipamentos e infraestruturas para conectá-las às redes de serviços urbanos complementares necessárias para essa expansão. A possibilidade de escassez relativa, devido à retenção especulativa de terras, por parte de poucos proprietários, esperando mudanças de uso de rural para urbano, por exemplo, confirma uma tendência secular à alta do terreno urbano.

Assim, a renda urbana absoluta tem origem na limitação da quantidade de terra incorporada à cidade, restringindo a quantidade de imóveis oferecida no mercado, fazendo com que a competição entre usuários aumente o preço do produto. Esse aumento de preço, sem que haja aumento de custos, traduz-se em lucro extraordinário, que é fruto das condições excepcionais do terreno à edificação, e, por isso, reverter-se-á em renda ao proprietário.

Essa modalidade de renda é compartiIhada por todos os terrenos, fixando o preço mínimo do solo nas cidades e sendo capaz de definir a porção do trabalho social canalizado nesse mecanismo. A magnitude da renda absoluta não tem origem na composição orgânica do capital no setor da construção, mas, sim, em uma relação de forças entre proprietários e aqueles que demandam direta ou indiretamente os terrenos urbanos (ibid.).

Essa magnitude torna-se mais ascendente, em contextos de expansão urbana, em cidades com atrativos de localização global que enfrentam limites de oferta de terrenos, por questões geográficas, por restrições ao fornecimento de infraestruturas, por regulações urbanísticas restritivas à expansão ou pela concentração da propriedade da terra periférica.

As modalidades de renda associadas à produção primária do solo são marcadas por um processo em que o capitalista construtor possui capital-dinheiro e quer transformá-lo em mais-dinheiro. 0 capitalista compra a terra do proprietário original, paga pelos meios de produção (máquinas, insumos e equipamentos) e pela força de trabalho assalariada, incorporando aspectos subjetivos e objetivos ao bem, de acordo com o usuário definido, para incrementar o preço e colocá-lo no mercado, configurando a articulação secundária do solo, que veremos a seguir. 


\section{As modalidades de renda na articulação secundária do solo urbano}

Diferentemente do caso das articulações primárias, em que o solo exerce um papel ativo na determinação do valor, no momento do consumo da mercadoria "espaço construído", o solo está agregado de maneira passiva, em virtude da imobilidade do artefato construído. A terra urbana articula-se de forma indireta ou secundariamente no processo de consumo do espaço construído, mas sua incidência é ativa sobre a possibilidade de desenvolvimento das atividades urbanas e um fator sobre a estruturação da renda da terra nas cidades.

Há uma determinada lógica em como se estrutura a distribuição espacial dos usos do espaço construído que segue determinados padrões, em que algumas atividades se concentram e se entrelaçam no território, buscando se complementar, se associar, se impor ou rechaçar outras atividades.

Essas atividades buscam organizar economicamente a grande concentração de meios produtivos e de força de trabalho presentes nas aglomerações urbanas. A concentração em massa de pessoas coloca a cidade também como espaço privilegiado de consumo de espaço urbano para fins de moradia. A produção desta é modulada de acordo com o poder de compra das distintas classes sociais e do papel desempenhado por elas na produção e distribuição do valor. A moradia é o mecanismo de reprodução geral do sistema capitalista, na medida em que permite a reposição física da força de trabalho. Os usuários finais são aqueles que adquirem o direito de uso da propriedade de suas edificações para o consumo do espaço construído para a habitação, tanto dos trabalhadores assalariados, quanto da classe dos consumidores de mais-valia. ${ }^{4}$

A terra urbana adquire uma articulação secundária fundamental no processo de industrialização e adequação dos espaços urbanos para a indústria. Além, disso, o papel histórico desempenhado como centro de trocas coloca a cidade como espaço privilegiado da circulação e das atividades de comércio de mercadorias. As estruturas de renda secundária do solo urbano estão relacionadas, sobretudo, aos usos dos espaços para essas três atividades urbanas principais: indústria, comércio/serviços e moradia.

A Renda Diferencial do Comércio (RDC) está relacionada à porção do capital encarregada de fazer circular a produção de mercadorias. Um setor que não produz valor, mas que extrai uma parte da mais valia gerada pelo capital produtivo, através de uma margem comercial cobrada sobre os preços dos fabricantes. Esse sobrepreço que o consumidor pagará será a base do lucro, influenciado pela magnitude da velocidade de rotação do capital comercial. Essa velocidade tende a se unificar pelos diferentes setores do comércio nas distintas localidades urbanas.

As atividades comerciais são distribuídas espacialmente através de um processo coletivo, externo ao controle do setor do comércio. Essa distribuição é objetiva e precisa, de modo a permitir uma identificação social dos consumidores a uma determinada localidade, que apresenta vantagens urbanas relativas. Os terrenos mais atrativos serão mais requisitados por permitir maior velocidade de rotação e maior taxa de lucro. A competição entre os capitalistas comerciais colocará o proprietário em condições privilegiadas de se apropriar do excesso da taxa de lucro média, sob a forma de renda diferencial do comércio. 
Importante considerar que a formação dessa renda não emerge do processo produtivo do espaço construído, por isso ela é secundária e considerada diferencial, por sua modulação ser gradual. Na medida em que os terrenos vão se distanciando dos pontos mais privilegiados para o comércio, eles apresentarão menores números de clientes, traduzindo-se numa menor rotação de capital e em um lucro relativamente menor.

Mesmo em cidades polinucleadas, essa graduação também se verifica, através do distanciamento relativo dos pontos mais vantajosos do comércio em cada núcleo. Pode haver, inclusive, um grau de diferenciação e magnitude entre esses núcleos pelas camadas de renda que buscam esses espaços comerciais, influenciando na rotatividade do capital e no sobrepreço cobrado pelos produtos. 0 comércio localiza-se junto aos competidores em zonas urbanas em que os consumidores já estão habituados a comprar mercadorias específicas. 0 preço em cada mercado cobre uma margem de lucro das empresas mais mal localizadas e um lucro extraordinário para as mais bem localizadas.

A renda diferencial do comércio pode ser observada em um plano empresarial de decisão de alocação comparativa entre três localidades, levando em conta a rotatividade do capital, de acordo com o número de rotações do estoque por ano. A melhor localização em termos de rotatividade de estoque para as vendas do comércio terá uma renda diferencial do solo associado ao uso do comércio e será parametrizada pelo lucro bruto da empresa.

No limite, o empresário pagará todo seu sobrelucro em relação à pior localidade, devido às capacidades de venda superiores. 0 aluguel formado será muito próximo ao lucro auferido pelo comércio nessa localidade e, por isso, a magnitude da renda será calculada em função do lucro. A renda absoluta urbana, de acordo com esse raciocínio, é definida pelo aluguel na pior localidade, cuja magnitude será expressa pela diferença entre o preço de mercado dos produtos da empresa mais mal localizada e o preço de produção (Singer, 1982).

Os capitalistas do comércio em pior localização apresentam uma rotatividade marginal do capital, regulando a margem de lucro para todo o comércio na cidade. Os preços mínimos dos fabricantes serão fixados segundo essa margem do mais mal localizado. Pela natureza heterogênea dos espaços urbanos, esse aspecto impede que os preços finais de uma mesma mercadoria se unifiquem pela cidade, sobretudo pela distribuição não uniforme dos consumidores por estrato de renda (Jaramillo, 2009).

Em algumas áreas da cidade, encontram-se compradores dispostos a pagar mais por uma mesma mercadoria, para evitar deslocamentos intraurbanos. Esse sobrepreço estaria relacionado a custos de transporte mais elevados do que aos aspectos da segregação social e da dimensão simbólica dos espaços. ${ }^{5} \mathrm{O}$ comércio que opera nessas áreas mais ricas pode desfrutar de margens comerciais maiores, traduzindo-se em maiores lucros e, consequentemente, em renda diferencial do comércio aos proprietários desses imóveis.

A Renda de Monopólio de Segregação está associada à moradia das classes que extraem o excedente social. 0 fenômeno da segregação socioespacial ocorre quando as classes mais ricas demarcam seus espaços construídos, excluindo as classes mais baixas, ao pagar uma espécie de "imposto privado". Esse pagamento adicional serve de distintivo social ou uma forma de identificação entre 
membros da mesma classe para se localizarem na cidade, segundo uma escala social. A forma como esse tipo de "imposto privado" se traduz em renda está relacionada a uma conotação socialmente positiva em determinados espaços, através de um mecanismo coletivo que independe da atuação de agentes individuais.

No modelo simplificado de Jaramillo (ibid.), considera-se apenas o consumo de moradia para a classe trabalhadora, em que a moradia consiste em um componente da reprodução da força de trabalho, e para as classes não trabalhadoras, em que a moradia aparece como consumo final de mais-valia. A segregação socioespacial, contudo, expande-se através das práticas de indivíduos com alto grau de acumulação, de acordo com a hierarquia social, pela capacidade de consumo, qualquer que seja a origem dessa renda, equivalendo às práticas habitacionais da burguesia, a classe que extrai excedente econômico.

O construtor produz os espaços, de acordo com o poder de compra das camadas sociais de renda, respeitando essa distribuição socioespacial e induzindo que a localização da moradia adquira uma significação social. Os incorporadores forjam e reforçam uma distinção do ato de morar longe das classes mais baixas e uma identificação de viver entre os mais ricos para que esse lucro seja gerado.

Nesse processo de explicitação da hierarquia social, os proprietários dessas localidades controlam esses mecanismos de diferenciação, cobrando um sobrepreço que se traduz em renda de segregação. As convenções sociais e os códigos de alocação de uso são determinantes para as interpretações sobre os aspectos da segregação socioespacial em uma cidade.
Nas cidades capitalistas de países periféricos, marcadas por profundas desigualdades de renda, essa separação radical da vida cotidiana entre as classes sociais gera uma estrutura da renda do solo em que é nítida a existência de uma renda de segregação que não está relacionada a um processo de produção nem a um setor de acumulação de capital não produtivo, como no caso do comércio.

Para a localização que produz diferenciação social ser monopolizada, o mercado é dominado pela demanda solvável (o preço determina o uso e não o inverso), como por exemplo, nas áreas residenciais exclusivas. Essa renda pode apresentar uma modulação gradual escalonada pela capacidade de consumo de cada estrato social, excluindo as camadas sucessivamente inferiores (ibid.).

Singer (1982) considera as condições de monopólio para a segregação social de moradia, devido às diferenças de infraestrutura e serviços urbanos, que exacerbam os preços das áreas bem servidas, bem como um fator associado ao prestígio social da vizinhança, que faz com que a classe média almeje a ascensão social e o afastamento das classes mais pobres, pagando um preço a mais por isso. 0 conceito de renda de monopólio pode ser aplicado também para o caso do comércio, quando em certas localidades, diante da ausência de competidores, o comerciante é capaz de cobrar acima dos preços de mercado dos concorrentes, pela exclusividade de vendas, tais como em shoppings, clubes, etc.

Esse ponto é importante porque ajuda a compreender a diferença da natureza da renda diferencial para a renda de monopólio. A diferencial é paga pelo sobrelucro que as empresas auferem pelos atributos locativos, enquanto a de monopólio depende da quantidade de 
indivíduos dispostos a pagá-la, a partir da repartição da renda pessoal e das necessidades criadas por promotores e incorporadores imobiliários (ibid.).

A Renda Diferencial de Moradia (RDM) refere-se ao consumo pela camada social que sofre os efeitos da segregação, os trabalhadores assalariados, que consomem espaços construídos em que não opera a renda da segregação. 0 consumo de moradia requer o entrelaçamento espacial de valores de usos complementares e a proximidade relativa aos locais de abastecimento, de reprodução coletiva da força de trabalho e de emprego.

Dada a heterogeneidade dos espaços construídos, esses valores complementares estão distribuídos desigualmente, levando a disparidades nos deslocamentos para o consumo de moradia. Nas distintas localizações incorrerão custos diferenciados para a apropriação de valores de uso comparáveis, sobretudo, os custos de transporte coletivo, o tempo de deslocamento e a magnitude do salário, que deve prever o consumo da moradia.

No salário fixado socialmente, estão previstos o custo do consumo de espaço construído e uma parcela adicional referente ao gasto em que a generalidade de trabalhadores deve incorrer para entrelaçar valores de uso urbano complementares à moradia. 0 trabalhador que conseguir se situar em lugares com melhor localização de usos complementares, que impliquem custos menores de deslocamentos, terá uma parte menor de seu salário destinado à habitação.

A estrutura espacial de valores de usos de uma cidade está fora do controle dos trabalhadores e dos capitalistas, que produzem habitação. O proprietário da terra urbana, que vender seu lote para os promotores imobiliários, exerce esse domínio sobre as condições de reprodução da força de trabalho. A competição por essa moradia com diferenciais de localização no mercado se transforma em renda diferencial de moradia.

Mediada pelos agentes produtores de espaços construídos (incorporador, promotor e construtor), o proprietário exerce uma relação de poder ao cobrar do trabalhador assalariado uma quantia superior ao valor da construção do espaço construído. Essa margem cobrada corresponde à diferença entre os custos que implica o consumo de moradia, em seu lote, e aqueles referentes aos terrenos que implicam maiores custos dos valores complementares.

Uma modalidade importante que surge nessa articulação do solo urbano para o consumo de moradia pela classe trabalhadora consiste na figura do capitalista arrendatário, que se especializa na circulação da mercadoria espaço construído, comprando do construtor e alugando aos trabalhadores. Note-se que aí há um elo maior da renda secundária do solo, em que o papel da localização dos lotes, diante dos valores complementares, é determinante: o capitalista construtor compra o lote do proprietário e produz espaço construído para o consumo de moradias populares, sem grandes diferenças de custos produtivos. O capitalista arrendatário, ao comprar essas mercadorias dos construtores e alugá-las para os trabalhadores assalariados, aparece como o agente que se apropria desse tipo de renda. ${ }^{6}$

No longo prazo, os custos de reprodução regulam-se pelas condições marginais e se nivelam pelos custos do trabalhador bem localizado, que paga em renda aquilo que o mais mal situado paga em transporte. Os salários devem ser compatíveis aos custos dos trabaIhadores mal localizados, em relação a essa 
complementaridade dos valores de usos associados ao consumo de moradia pela força de trabalho. A renda do solo consiste na diferença entre as condições médias, em que os proprietários detêm essa porção do valor.

Os capitalistas, em geral, pressionam o Estado a resolver essa tensão com os proprietários urbanos, induzindo-o a diminuir essa heterogeneidade de custo de deslocamentos, através de ações indiretas, com investimento em transporte público, subsídios tarifários, políticas de densificação, normas urbanísticas, etc. Além de ações diretas para limitar a capacidade do proprietário de exigir essa renda, com medidas também sobre os capitalistas arrendatários, que estabelecem um sobrepreço acima do preço de produção da habitação, equivalente aos custos de transporte.
Os usuários finais pagam pelos três componentes dos serviços de moradia: o preço de produção de imóvel, os custos de transporte e o sobrepreço que se converte em renda ao proprietário. 0 preço do imóvel consiste no agregado do preço de construção e a renda diferencial de moradia, tendendo a diminuir conforme se distancia das áreas centrais, numa magnitude inversa ao custo de transporte. Se a localização (sintetizando a acessibilidade e as amenidades locais) é melhor, o construtor pode cobrar o preço final maior, e o proprietário original beneficia-se, auferindo uma renda maior por seu terreno.

Na Gráfico 2 vemos as rendas aditivas (RAU e RD) ou competitivas (RDC ou RDM) de acordo com a distância do centro, onde os preços são mais elevados, situando os limites

Gráfico 2 - Relação aditiva e competitiva entre rendas urbanas

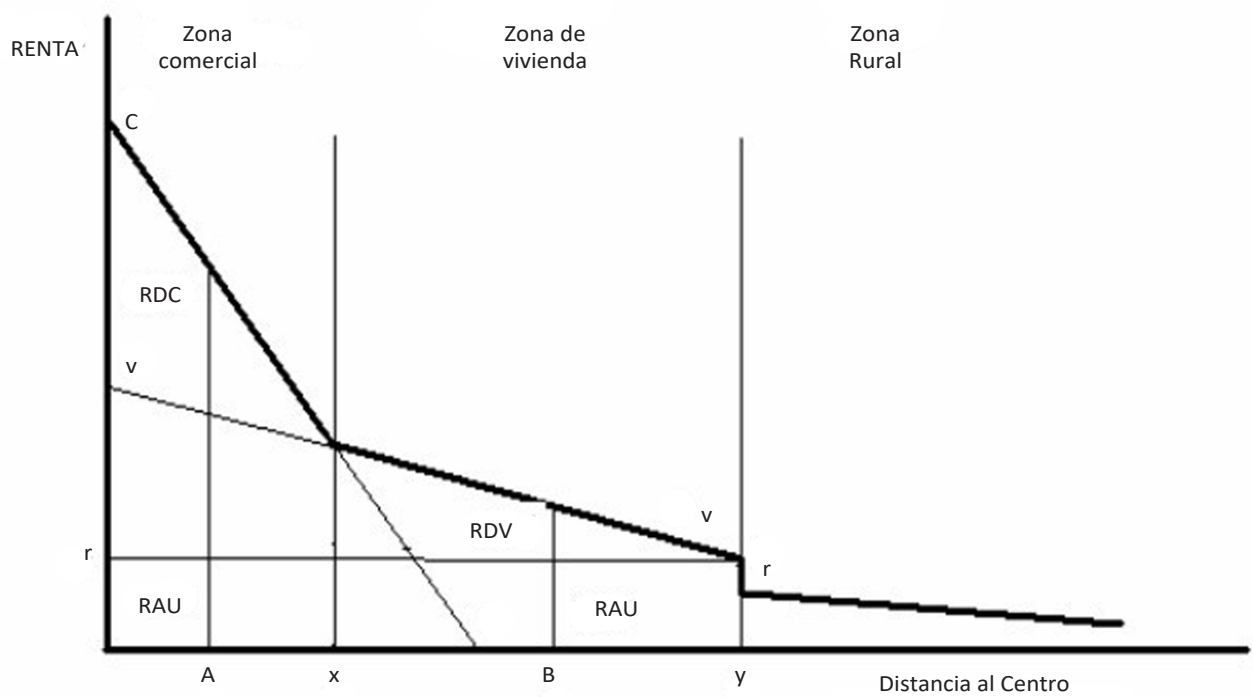

Fonte: Jaramillo (2009).

Obs.: O conteúdo do gráfico pode ser traduzido como: zona de vivienda equivale à zona residencial e renda diferencial de vivienda (RDV), à renda diferencial de moradia (RDM). 
entre as zonas comerciais, zona residencial e zona rural. É possível perceber que a RAU é uniforme e se forma a partir do limite com a área rural. A RDC impõe-se perante a RDM que está deslocada em relação ao centro, onde a rotatividade do capital é maior, capaz de multiplicar o lucro e formar uma renda diferencial.

A Renda Diferencial e de Monopólio Industrial é gerada pela localização das indústrias, na cidade. Os industriais são induzidos por políticas urbanísticas a se situarem em terrenos afastados dos centros para impedir congestionamentos e gargalos (externalidades negativas), gerando uma possibilidade de renda extra aos proprietários dessas terras.

Por ser indiferente à localização, o industrial tende a se instalar em áreas residuais menos disputadas pelas demais atividades econômicas e com maior oferta de espaços livres disponíveis. Geralmente, essas condições são encontradas nas regiões urbanas periféricas, que ainda apresentam rendas do solo mais baixas. A renda diferencial da indústria é determinada pelas vantagens aglomerativas e de comunicação com as redes de empresas fornecedoras e prestadoras de serviços, mas é limitada pelas normas urbanas. As atividades industriais podem também alavancar as rendas diferenciais do comércio e de moradia, situando a força de trabalho próxima ao local de produção.

0 Estado induz que as indústrias se instalem nas franjas urbanas, tanto para minimizar as externalidades negativas (poluição do ar, do solo, sonora, visual, etc.) quanto para garantir a disponibilidade suficiente de terras necessárias à complexidade de atividades econômicas complementares e articuladas às indústrias, cobrando tributos especiais para esses terrenos, fazendo surgir a renda de monopólio industrial.

Portanto, nas cidades, a renda total de cada lote é estruturada por uma combinação de várias rendas que, quando capitalizadas, agrega uma parcela de valor sobre os preços dos espaços construídos. 0 preço do solo urbano (PS) é, então, uma função da renda da terra (R) sobre a taxa de lucro média (g), expresso na seguinte equação: $P S=R / g$. $O$ que significa que o preço do solo urbano apresenta uma relação inversa à taxa de lucro média na economia. É o resultado de um exercício imaginário do proprietário comparar a propriedade da terra à posse de um capital. A renda da terra passa a ter uma determinada magnitude comparada ao rendimento de um capital de tamanho similar, e o preço do solo adquire uma tendência à alta secular, devido a uma característica intrínseca do capitalismo, que é a perspectiva histórica de um movimento decrescente da taxa de lucro média no longo prazo ${ }^{7}$ (Jaramillo, 2009).

No Quadro 1 apresentamos as estruturas, articulações e modalidades da renda da terra e sua manifestação no contexto agrícola e urbano, levando em conta o arcabouço teórico selecionado. A sistematização da renda da terra e a formulação futura de modelos econômicos podem vir a ilustrar melhor seus efeitos sobre variáveis macroeconômicas e o desenvolvimento regional. Este quadro permite que teçamos as considerações finais, na sequência, relacionando-as com a estratégia de política fundiária em marcha no País. 
Quadro 1 - Estruturas, articulações e modalidades da renda da terra

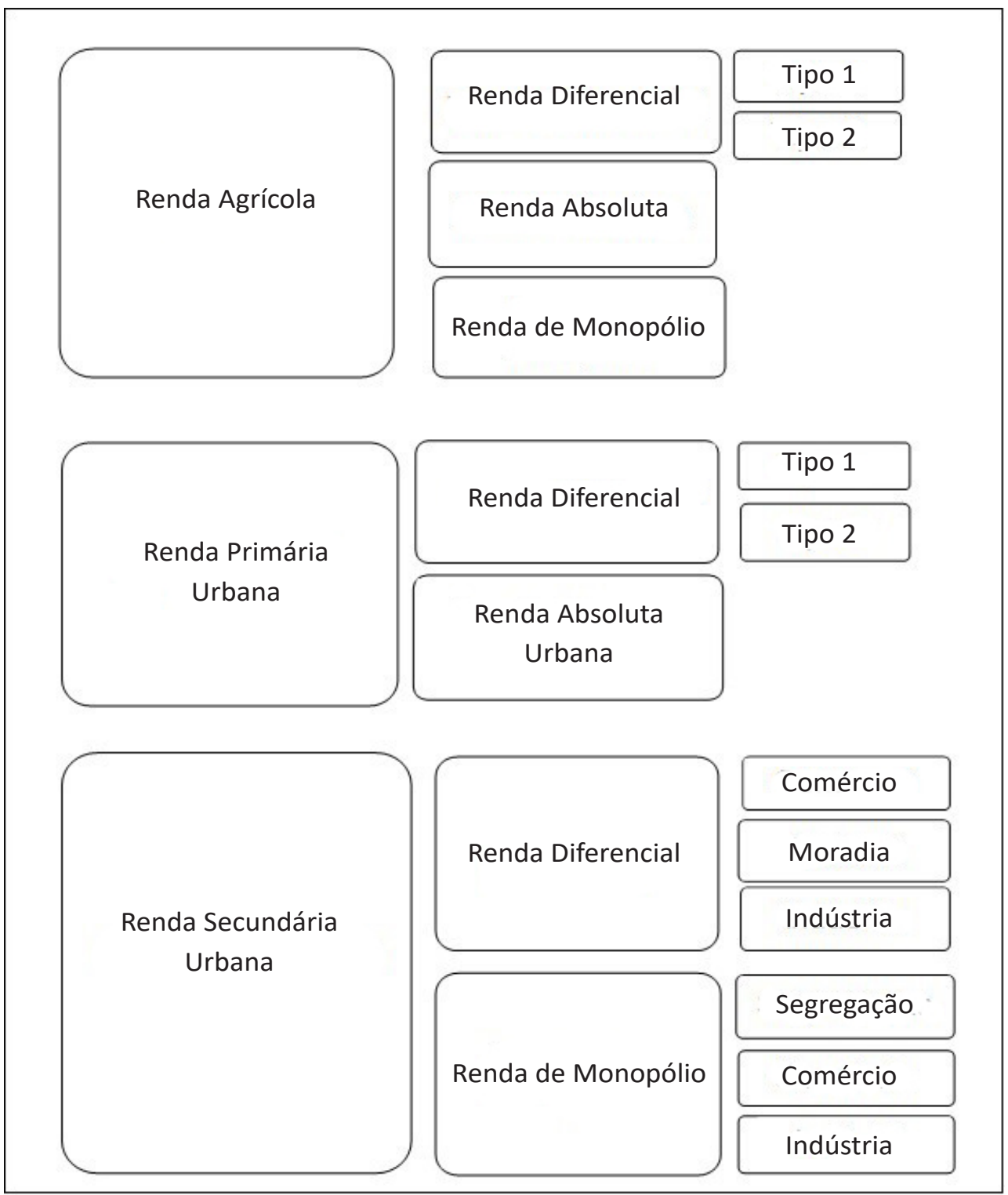

Fonte: elaborado a partir de Jaramillo (2009). 


\section{Considerações finais sobre a aquisição de terras pelo capital estrangeiro}

Expostas as modalidades de renda da terra sistematizadas no Quadro 1, podemos refletir o que poderá acontecer com a magnitude dessas rendas com a provável aprovação do projeto de lei n. 2.963/2019, ${ }^{8}$ que tramita no Senado Federal, visando revogar a proteção na aquisição de imóvel rural por estrangeiros. Tal Projeto de Lei $(\mathrm{PL})$ pode permitir a entrada maciça de capitais internacionais no País, alterando profundamente o acesso à terra e à divisão do valor.

O modelo econômico atual totalmente pautado no capital externo como única garantia de desenvolvimento esconde uma agenda que compromete a soberania, a democracia, o desenvolvimento nacional e os interesses do povo, dificultando o acesso à terra, o desenvolvimento interno e a reforma agrária, baseada na agricultura familiar. Tal política não visa apenas facilitar o ingresso de agroindústrias transnacionais, como defende o $\mathrm{PL}$, pois, como vimos, haverá aí um mecanismo claro de apropriação indevida do fundo coletivo de valor interno criado no País, mediante apropriação de parte da mais-valia geral produzida na economia.

Essa política fundiária poderá permitir o monopólio de terras pelo capital estrangeiro, desconsiderando o fato de que a renda da terra será apropriada de um fundo de valor coletivo. 0 acesso à terra historicamente sempre foi excludente e facilitado para uma elite branca de origem estrangeira. No marco das políticas fundiárias brasileiras inauguradas com as capitanias hereditárias, essa política consegue ser ainda mais radical do ponto de vista colonial, ao facilitar a aquisição de até um quarto (art. 8 do PL), com a possibilidade de autorizar além desse limite, mediante decreto legislativo do Congresso Nacional (art. 12), do território de um município ao capital estrangeiro. Isso causará um impacto sobre a magnitude de todas as modalidades de renda da terra apresentadas, inclusive as rendas do solo urbano.

A regulamentação dessa norma geral tem por objetivo disciplinar a aquisição, as modalidades de posse e o cadastro de propriedade rural por pessoa física ou jurídica estrangeira. Ainda que prevendo a obediência aos princípios da função social da propriedade e a autorização prévia do Conselho de Segurança Nacional sobre alguns quesitos, o PL apresenta vários pontos que merecem ser ressaltados, a seguir, por permitir a:

- aquisição de faixas em áreas de fronteira; em áreas ecológicas, com recursos hídricos, energéticos, minerais, da fauna e da exploração de florestas;

- apropriação de faixas como a do bioma amazônico; exploração de parques naturais e formação de enclaves turísticos e de colônias de povoamento e de exploração;

- possibilidade de controle fundiário local, regional e nas áreas de expansão das fronteiras agropecuárias por uma única nação com interesses contrários ao do povo brasileiro;

- reversão do controle da terra por uma elite brasileira branca de imigrantes de origem europeia por estrangeiros;

- possibilidade de influenciar uma escassez relativa, devido à retenção especulativa de terras, por parte de poucos proprietários, esperando mudanças de uso de rural para urbano; 
- possibilidade de arrendamento e subarrendamento e apropriação das rendas da terra agrícola diferenciais tipo 1 (fertilidade e localização), tipo 2 (intensidade de capital), renda absoluta e renda de monopólio;

- possibilidade de influenciar a renda do solo urbano, sobretudo em cidades nas franjas das áreas rurais adquiridas. Como a Renda Absoluta Urbana é uniforme e se forma a partir do limite com a área rural, ela é compartilhada por todos os terrenos, fixando o preço mínimo do solo nas cidades e sendo capaz de definir a porção do trabalho social canalizado nesse mecanismo.

A renda urbana absoluta tem origem na limitação da quantidade de terra incorporada à cidade, restringindo a quantidade de imóveis oferecida no mercado, fazendo com que a competição entre usuários aumente o preço do produto. A magnitude da renda absoluta não tem origem na composição orgânica do capital no setor da construção, mas, sim, de uma relação de forças entre proprietários e aqueles que demandam direta ou indiretamente os terrenos urbanos. Essa magnitude torna-se mais ascendente, em contextos de concentração da propriedade da terra periférica.
No longo prazo, o capital estrangeiro poderá ter domínio sobre o preço do solo urbano que apresenta uma relação inversa à taxa de lucro média na economia. 0 capital estrangeiro terá o monopólio da posse de terras e produzirá rendas de monopólio para uma demanda solvável (o preço determina o uso e não o inverso), ampliando a exclusão econômica e urbanística de uma ampla camada da população brasileira nas metrópoles.

Os proprietários estrangeiros estarão em condições excepcionais, através da competição entre capitalistas, de se apropriarem do sobrelucro sob a forma de renda da terra de uma parte da mais-valia apropriada do fundo geral de acumulação de capital, em seu conjunto. 0 resultado disso no longo prazo pode ser a substituição da classe dos proprietários de terra de tradição rentista e patrimonialista e até da burguesia produtiva nacional, inaugurando uma nova etapa da agenda colonial posta em solo brasileiro, em que o capital estrangeiro conseguirá ajustar a composição orgânica do capital na economia brasileira.

\section{[I] https://orcid.org/0000-0002-9062-9173}

Universidade Federal do Rio de Janeiro, Programa de Pós-Graduação em Urbanismo, Laboratório de Patrimônio Cultural e Cidades Contemporâneas. Rio de Janeiro, RJ/Brasil.

araujoedmar1@gmail.com 


\section{Notas}

(1) A Composição Orgânica do Capital reflete o grau de complexidade técnica produtiva, através da proporção entre o Capital Constante e o Capital Total.

(2) A Inglaterra apresentava, no Antigo Regime, as estruturas sociais, econômicas e políticas ideais para compreender o fenômeno social da renda da terra, com um estatuto de propriedade privada da terra que possibilitava a conversão de lucro em renda. Essa renda feudal ou pré-capitalista foi substituída por uma poderosa classe de proprietários de terras, em rendas capitalistas (Jaramillo, 2009).

(3) Modelos utilitaristas de alocação da economia espacial urbana determinados pela distância do mercado em relação à estrutura produtiva enfatizam a centralidade como catalisadora de rendas fundiárias. A cidade é estruturada em anéis concêntricos, no qual o preço do solo vai diminuindo a partir da região central de negócios, fruto da competição interpessoal. A explicação do preço da terra relacionado à funcionalidade urbana e aos efeitos de aglomeração apresentou avanços no instrumental técnica, mas resultados tautológicos e contraditórios do ponto de vista socioespacial.

(4) Esses usuários finais são também outros capitalistas, em seus ramos de acumulação, caracterizados como industriais e comerciantes. A indústria representa a modalidade produtiva mais avançada capaz de articular uma rede de firmas, formando uma unidade complexa de produção de valor.

(5) Em cidades socialmente estratificadas, nas áreas de ocupação das classes mais abastadas, as mercadorias são mais caras do que o preço de mercado pela capacidade do poder de compra superior e para afastar desses espaços consumidores mais pobres.

(6) O arrendatário assume as tensões envolvidas nesse processo, uma vez que essa renda aumenta o custo de reprodução da força de trabalho, pressionando um aumento dos salários. Há uma tensão entre o conjunto de capitalistas, os arrendatários e os proprietários urbanos, que buscam se apropriar de parte do valor.

(7) O comportamento decrescente da taxa de lucro, ao longo do tempo, resulta de uma tendência histórica de aumento da composição orgânica do capital e do capital constante, via inovação tecnológica, e uma diminuição mais que proporcional de capital variável, representado pelo desemprego de mão de obra humana. Como apenas o trabalho vivo produz mais-valia, o aumento da produtividade do trabalho leva a uma diminuição de valor por produto e a um aumento momentâneo do lucro no curto e médio prazo. Os capitalistas intensivos em mão de obra são retirados do mercado, levando a uma diminuição da mais-valia geral, a uma concentração de capital e a uma diminuição da taxa de lucro no longo prazo.

(8) Regulamenta o art. 190 da Constituição Federal, altera o art. 10 da lei n. 4.131, de 3 de setembro de 1962, o art. 1o da lei n. 5.868, de 12 de dezembro de 1972, e o art. 60 da lei n. 9.393, de 19 de dezembro de 1996, e dá outras providências (Senado Federal, 2019). 


\section{Referências}

ALMEIDA, R. e MONTE-MÓR, R. (2017). Renda da terra e o espaço urbano capitalista contemporâneo. Brazilian Journal of Political Economy - Revista de Economia Política. São Paulo, v. 37, n. 2, pp. 417-436.

BOTELHO, A. (2008). A Renda Fundiária Urbana: uma categoria de análise ainda válida. Revista GEOgrafia. Niterói, UFF, ano IX, n. 19, pp. 23-40.

CAMPANARIO, M. (1981). Land Rent and the Reproduction of Labor force: some evidence from São Paulo. Tese de Doutorado. Nova York, Cornell University.

FERREIRA, J. (2005). A cidade para poucos: breve história da propriedade urbana no Brasil. In: SIMPÓSIO: INTERFACES DAS REPRESENTAÇÕES URBANAS EM TEMPOS DE GLOBALIZAÇÃO. Unesp e Sesc. Anais... Bauru.

GAIO, D. (2012). A participação do Estado na formação do valor do solo urbano e os mecanismos de recuperação de mais-valias no Brasil. Cuaderno Urbano. Espacio, Cultura, Sociedad, v. 12, n. 12, pp. 22-42.

HARVEY, D. (1980). Justiça social e a cidade. São Paulo, Hucitec.

JARAMILLO, S. (2009). Hacia una teoría de la renta del suelo urbano. Bogotá, Ediciones Uniandes.

KOWARICK, L. (1979). A espoliação urbana. Rio de Janeiro, Paz e Terra.

LEFEBVRE, H. (2000). La production de l'espace. Paris, Éditions Anthropos.

LIPIETZ, A. (1973). Le tribut foncier urbain. Paris, Maspero.

LOJKINE, J. (1979). “Existe uma renda fundiária urbana?” In: FORTI, R. (org.). Marxismo e Urbanismo Capitalista: textos críticos. São Paulo, Editora Ciências Humanas.

MARX, K. (1996). O Capital. Os Economistas. Coleção Os Pensadores. São Paulo, Nova Cultural.

PRETECEILLE, E. (1974). La planification urbaine. Les contradictions de l'urbanisation capitaliste. Economie et Politique. Paris, n. 236, pp. 94-114.

RICARDO, D. (1996). Princípios de Economia Política e Tributação. Os Economistas. Coleção Os Pensadores. São Paulo, Nova Cultural.

SENADO FEDERAL (2019). Projeto de lei n. 2963. Disponível em: https://legis.senado.leg.br/sdleggetter/documento?dm=7955264\&ts=1576881286313\&disposition=inline. Acesso em: $13 \mathrm{fev}$ 2020.

SINGER, P. (1982). “O uso do solo urbano na economia capitalista”. In: SINGER, P. A produção capitalista da casa (e da cidade) no Brasil industrial. São Paulo, Alfa-Omega.

TOPALOV, C. (1981). "Elementos para una teoría de las rentas del suelo urbano". In: TOPALOV, C. La urbanización capitalista. Cidade do México, Edicol.

Texto recebido em $20 / \mathrm{fev} / 2020$

Texto aprovado em 24/abr/2020 